\title{
Size-discrimination deficit in primates with inferotemporal lesions ${ }^{1}$
}

\author{
LINDA OLSON, ROBERT W. LEARY, UNIVERSITY OF OREGON \\ RICHARD F. THOMPSON ${ }^{2}$, UNIVERSITY OF OREGON MEDICAL SCHOOL
}

Four species of testwise monkeys with extensive ablations of posterior neocortex (including inferotemporal tissue) were impaired in a size discrimination problem. The deficit, which was persistent after 1200 trials and two testing procedures may be attributed to a loss in ability to classify visual information.

Discriminations requiring choices between stimuli differing slightly in one dimension have reliably shown a performance decrement in primates with bilateral temporal ablations. Such an impairment has been reported for discriminations between shades of gray (Mishkin \& Pribram, 1954), brightnesses (Pinto et al, 1957), and sízes (Mishkin \& Hall, 1955; Wilson \& Mishkin, 1959). The purposes of the present investigation were first, to replicate the earlier size discrimination results using experienced primates (Experiment 1), and second, to separate the previously entangled effects of order of presentation and discrimination difficulty (Experiment 2).

Subjects

Ss were 34 experimentally sophisticated, physically mature monkeys of four species-nine Macaca mulatia, seven Macaca nemestrina, seven Cebus apella, six Saimiri scuiurea. Three apellas and four of each of the other species had undergone a bilateral two-stage ablation of posterior neocortex about five months before the present study. In the rhesus group, the planned cortical lesion was bounded posteriorly by the lunate sulcus and anteriorly by the lateral and superior temporal sulci. Ventrally, the lesion extended medial to the occipitotemporal sulcus. Extirpations included von Bonin's areas PG, PF, OA, TE, and portions of TF and TH. The relative amount of cortex ablated was approximately the same for all species. Complete histological evidence is not yet available. Only three operated and three normal apella monkeys were tested in Experiment 2.

Apparatus

Ss were tested in a standard WGTA, and the stimulus objects were placed on a two-hole white test tray with 10-1/2 in. between foodwells. Ss were presented with several pairs of $1 / 4$ in. thick Masonite discs which had been painted flat black. Members of each pair differed only in diameter.

Procedure

Preliminary training. Ss were given 50 trials daily on a discrimination between a 5 in. and 3 in. disc until a criterion of 18 correct responses in 20 consecutive trials was achieved. The smaller stimulus was rewarded. A $S$ which failed to reach criterion within 300 trials was required to reach criterion on 6 vs 2 in. and then on a 6 vs 3 in. problem before being returned to the original problem.

Experiment 1. Ss received 50 trials daily on a five day discrimination test series which paired the rewarded 3 in. disc (correct) with a $4,3-3 / 8,3-1 / 8$, $3-1 / 16$ in. disc or with another 3 in. disc, respectively. The final pairing of stimuli with identical diameters served as a control for cues. The entire discrimination series was then repeated. Object position was randomized with two restrictions-equal left and right placements of the correct stimulus occurred every 12 trials, and no more than three consecutive rewards were placed to the left or right.

Experiment 2. Six months after completion of Experiment 1, Ss were retrained on the 5 vs 3 in. discrimination. All discrimination pairs of Experiment 1, including the training discrimination, were presented daily for 12 days. Each session began with five trials on the training discrimination. This was followed by a semi-random presentation of the six problems, eight trials per problem.

Results

Preliminary training. Analysis of variance yielded no significant differences between operated and control animals for either trials or errors to criterion. Criterion was reached within 150 trials with the exception of two operated Ss, a squirrel and a pigtail, which required additional training.

Experiment 1. A multifactor analysis of variance of the test discrimination series, excluding the 3 vs 3 in. data, indicated that operated animals made significantly more errors than did their controls ( $p$ $<.01)$. The deficit was consistent across the discrimination series with a maximum separation between groups on the 3-3/8 comparison. Analysis of the control discrimination indicated that neither group utilized extraneous cues. Also significant were problems, problem by lesion interaction, and species. Stimulus pairs with the smallest diameter difference resulted in the most errors $(p<.001)$. A combination of the problem effect with the lesion effect accounts for the moderately significant interaction $(p<.05)$. The species, ranked in order of mean performance (from best to worst) were apella, rhesus, pigtail, and squirrel. Mann-Whitney tests showed that apella and rhesus groups, although not different from each other, were superior to the squirrel monkeys $(p<.02)$. The pigtails fell between the two extremes. 


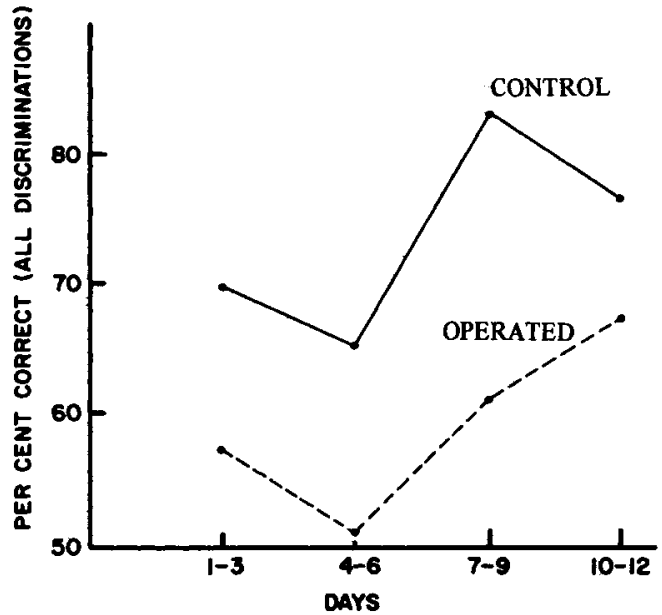

Fig. 1. Lesion effect and performance improvement, Experiment 2.

Experiment 2. Despite procedural differences, results comparable with those of Experiment 1 were obtained. Operated Ss made more errors $(t=3.37$, $p<.025)$. Both operated and control Ss reduced their average errors from Day 1 to Day 12 (Fig. 1 ).

Discussion

Both control and operated animals learned the easy preliminary size discrimination efficiently, but operated Ss performed at a significant decrement on the difficult discriminations. Although the exact nature of the deficit is obscure, some hypotheses may be regarded as unlikely. The suggestion that overtraining will overcome the loss in discrimination is rendered doubtful by the continuing deficit noted in Experiment 2 at the end of 1200 trials. The typical experimental procedure, employed in Experiment 1 , is conducive to the speculation that the lesion causes Ss to forget the nature of the problem during the one or two days which intervene between easier and harder problems. Within a given day in Experiment 2, operated Ss concurrently solved the 5 in. and 4 in. problems and were noticeably impaired on the $3-1 / 8$ and $3-1 / 16$ in. problems.

The size discrimination results may perhaps be regarded as a perceptual deficit of the type described by Butter (1963). Inferotemporal Ss learned little about the distinctive features of the visual stimuli and showed broad generalization gradients. It is possible that removal of certain parts of the temporal lobe produces impoverished classification of visual information.

\section{References}

BUTTER, C., MISHKIN, M., \& ROSVOLD, H. E. Stimulus generalization in monkeys with inferotemporal and lateral occipital lesions. In D. I. Mostofsky (Ed.), Stimulus Generalization. Stanford: Stanford University Press, 1965, 119-131.

MISHKIN, M., \& HALL, M. Discrimination along a size continuum following ablation of the inferior temporal convexity in monkeys. J. comp. physiol. Psychol., 1955, 41, 97-101.

MISHKIN, M., \& PRIBRAM, K. Visual discrimination performance following partial ablations of the temporal lobe: I. Ventral vs. lateral. J. comp. physiol Psychol, 1954, 47, 1420.

PINTO, T., SANTIBANEZ, G, GONZALES, C., \& VINCENCIO, E. Changes in behavior and discrimination performance after selective ablations of the temporal cortex. J. comp. physiol Psychol., 1957, 50, 379-385.

WILSON, W. A., \& MISHKIN, M. Comparison of the effects of inferotemporal and lateral occipital lesions on visually-guided behavior in monkeys. J. comp. physiol Psychol., 1959, 52, 10-17.

\section{Notes}

1. Research supported in part by NSF Grant G-15603 to R. W. Leary and R. F. Thompson, and in part by PHS Career Award MH-K3-6650 to R. F. Thompson. Experiment 1 is based on a thesis for the M. S. degree at University of Oregon submitted by Linda Rogers (Olson). 2. Now at University of California at Irvine. 